Available online on 15.09 .2020 at http://jddtonline.info
Open Access to Pharmaceutical and Medical Research
unrestricted non-commercial use, provided the original work is properly cited

Open $\odot$ Access

Research Article

\title{
Drug Utilization Study on Oral Contraceptives provided from Social Security, Buenos Aires-Argentina: Risk and cost analysis according to the type of combination used
}

\author{
${ }^{1} \mathrm{PhD}$, National University of La Plata- Scientific Research Commission, Argentina \\ ${ }^{2}$ MD, Buenos Aires Social Security (IOMA), Argentina \\ ${ }^{3}$ BS, National University of La Plata- Scientific Research Commission, Argentina \\ ${ }^{4}$ MD. Buenos Aires Social Security (IOMA), Argentina \\ 5 PhD Buenos Aires Social Security (IOMA), Argentina \\ 6 PhD National University of La Plata-CONICET, Argentina
}

Lupe Marin 1*, Luis Blanco 2, Gina Marin ${ }^{3}$, Sergio Agüero 4, Mariana Pagnotta 5, Gustavo H. Marin 6*

\begin{abstract}
Oral contraceptive pill is the most prescribed option to avoid birth-rate around the world. It is a combination of estrogens/progestin. Unfortunately, new combinations raise the risk of thrombosis. To determine the prescription profile and the incidence of thro mbotic events associated to oral contraceptive use, we developed the present study.

Method: It is a drug utilization study among beneficiaries of Buenos Aires Social Security Organization. Variables studied were age, sex, combination consumed, doses, co-morbidities, thrombotic events.

Results: 69,653 women were enrolled in the study. 66,043 of them (94.84\%) used new progestogen generation combination (desogestrel, gestodene, drospirenone,) while 3610 (5.18\%) used either levonorgestrel or norgestrel as progestin. The number of thrombotic events (either depth vein thrombosis of lower limbs, thromboembolism or arterial thrombosis) was 77 (75 with new progestin and 2 using $1^{\text {st }} / 2^{\text {nd }}$ generation options). Adjusting these values to 100,000 users; the occurrence of thrombotic events were doubled with new generation proge stins when compared to older options. The price of the new generation combinations were 10.2 times more expensive that the safer ones.

Conclusion: Among the beneficiaries of Buenos Aires State Social Security, the users of oral contraceptives with new generation progestin denote a greater risk of thrombotic events when compared with users of levonorgestrel or norgestrel. Public reproductive health policies that provide contraceptives to the population are crucial in guaranteeing rights such as avoiding unwanted pregnancies and reproductive planning. However, the combinations provided should not expose population to additional and unnecessary risks.
\end{abstract}

Keywords: oral contraceptives, thrombosis, progestin, risk, public health

Article Info: Received 19 July 2020; Review Completed 23 Aug 2020; Accepted 03 Sep 2020; Available online 15 September 2020

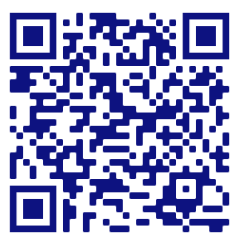

\section{Cite this article as:}

Marin L, Blanco L, Marin G, Agüero S, Pagnotta M, Marin GH, Drug Utilization Study on Oral Contraceptives provided from Social Security, Buenos Aires-Argentina: Risk and cost analysis according to the type of combination used, Journal of Drug Delivery and Therapeutics. 2020; 10(5):198-201 http://dx.doi.org/10.22270/jddt.v10i5.4315

Gustavo H. Marin. National University of La Plata-CONICET, Calle 60 y 120 (1900), La Plata, Argentina

\section{INTRODUCTION}

Oral contraceptive pills are the most popular birth control method worldwide used among reproductive-aged women ${ }^{1}$. For its proven efficacy to avoid ovulation and birth-rate the preferred option by prescribers, with the exception of breastfeeding period, is the combined oral contraceptive pill containing estrogens and progestogen compounds (CEPCs) ${ }^{2}$.
Despite its reliable contraception action, this type of pills may present side-effects that include sodium and water retention, hirsute, headaches and/or venous thrombosis 3 . Although this last side-effect is infrequent (only 1-5 events per 10,000 women-years), it constitutes a dangerous adverse effect due to its serious consequences on health, which sometimes even involve putting women's lives at risk. However, different combination pills show different vessel 
clotting obstruction tendencies, and thereby, dissimilar venous thrombosis risk. Even though the risk estrogens (usually ethinyl-oestradiol -EE-) dose ( $>30 \mathrm{ug}$ ) has a harmful effect on coagulation, the progestin component is actually the key point to differentiate the probability of suffering this serious adverse effect.

Several studies have indicated that low-dose CEPCs, containing a combination of $30 \mu \mathrm{g}$ EE and $150 \mu \mathrm{g}$ desogestrel, had a higher risk of venous thromboembolism (VTE) than those containing $30 \mu \mathrm{g}$ EE and $150 \mu \mathrm{g}$ levonorgestrel ${ }^{4-8}$. Given that desogestrel, and newer progestogen generation -like gestodene, drosperinone or cyproterone per se, administered as progestin-only contraceptive- does not show any procoagulant effect and does not increase the risk of suffering $\mathrm{VTE}^{9}$, the increasing of the risk of VTE between EE-desogestrel vs EE-levonorgestrel can only be attributed to a different modulation of the procoagulatory effect of EE, exerted by the two type of generation progestins ${ }^{10-14}$.

Indeed, progestins may counteract the procoagulant effects of estrogen to varying degrees. Many studies $4,15,16$ indicated that progestogens with a high androgenic potency, antagonize the risk of VTE associated with EE more than newer progestins ${ }^{6-8}$. For this reason, contraceptives containing EE associated with "nor" compound (levonorgestrel, norgestrel or norgestimate) record a threefold increase in the risk for a VTE event ${ }^{2,17}$, which rises to a sixfold increase when the contraceptive contains desogestrel, gestodene, drospirenone, or cyproterone acetate ${ }^{2,6,7}$. Hence, it could be said that the new progestogen generation duplicates the risk of thrombosis in relation to old progestogen generation, like norgestrel or levonorgestrel when combine with EE.

We can stand then, that while all combined monophasic oral contraceptive pills have the same effectiveness on preventing unwanted pregnancies, a group of them containing new progestogen generation compounds increases significantly thrombosis and thromboembolism risk.

Knowing this fact, we conducted a research study to determine the type of contraceptives prescribed and financed by the Social Security of the State of Buenos Aires, and the thromboembolic events related to these medicines

\section{PATIENTS AND METHODS}

Type of Study: This is an observational-analytical drug utilization study, with retrospective follow up of each case along time, in order to detect side effect associated to treatment received.
Institution: Buenos Aires Social Security Public Health Organization -SS.

Period of Study: 01-01-2016 to 31-12-2016 (with a follow up to 31-12-2017)

Universe of Analysis/Sample: The universe of analysis consists on women who have used oral pills as a contraceptive method, having obtained them through the state of Buenos Aires Social Security System (SS), during the period of study. All the female under program were considered in this research, hence sample matched the universe.

Variables: age, sex, type of drug consumed, doses, drug consumption period, thrombotic events, co-morbidities.

Statistical Analysis: The data were analyzed using the statistical program, SPSS v.17. For the analysis, the Kolmogórov-Smirnov test was used to know the normality of the variables studied. Quantitative variables were presented as mean values, standard deviation, and minimum and maximum 95\% confidence interval, while those without normal distribution were presented in median. The qualitative variables were presented in percentages for each parameter explored. To compare means values of parametric variables, the Student's t-test was used; Mann-Whitney Utest was performed for non-parametric variables, and the Chi-square test was used to determine the association between variables. $\mathrm{P}<0.05$ was considered statistically significant.

Ethical considerations: The Ethics Committee of Scientific Research Committee of Buenos Aires evaluated the proposal of the present work and considered that no ethical incompatibilities were detected CIC-012/16.

\section{RESULTS}

Buenos Aires public Social Security system covers all public employees and their families which constitutes 2,1 millions of beneficiaries.

The Social Security holds a coverage program (called "Ser") that provides to childbearing age females any type of oral contraception prescribed by GPs, for free (100\% coverage).

The number beneficiaries of the program using contraceptive pills were 69,653 women. 66,043 of them (94.84\%) used a combination containing new progestogen generation (desogestrel+ ethinylestradiol, ethinylestradiol+ gestodene, drospirenone+ethinylestradiol,) while 3610 $(5.18 \%)$ used either levonorgestrel or norgestrel as progestogen combination (estradiol-noretisterona, levonorgestrel+ethinylestradiol) (table 1).

Table 1: General treatment data

\begin{tabular}{|c|c|c|c|}
\hline Parameter & $\begin{array}{c}\text { Total no of } \\
\text { beneficiaries }\end{array}$ & $\begin{array}{c}\text { no of beneficiaries under "new" } \\
\text { progestogen treatment } \\
\text { combination }\end{array}$ & $\begin{array}{c}\text { no of beneficiaries under } \\
\text { “old" progestogen } \\
\text { treatment combination }\end{array}$ \\
\hline Beneficiaries & 69,653 & 66,043 & 3610 \\
\hline$\%$ & 100 & 94.84 & 5.18 \\
\hline
\end{tabular}


The prices of the new progestogen were in average 10.22 times more expensive than old combinations (range 2.54-17.7) (table 2).

Table 2: Price analysis of the treatments provided

\begin{tabular}{|c|c|c|c|c|c|c|}
\hline Progestogen* & Type & DDD & $\begin{array}{l}\text { Daily } \\
\text { Price }\end{array}$ & $\begin{array}{l}\text { Monthly } \\
\text { cost }\end{array}$ & $\begin{array}{c}\text { Annual cost } \\
\text { per patient }\end{array}$ & $\begin{array}{c}\text { Annual cost for all } \\
\text { beneficiaries** }\end{array}$ \\
\hline drospirenone & \multirow{3}{*}{$\begin{array}{c}\text { New } \\
\text { Generation }\end{array}$} & $3 \mathrm{mg}$ & 2.54 & 71.31 & 855.72 & $59,603,465$ \\
\hline desogestrel & & $0.150 \mathrm{mg}$ & 0.22 & 14.18 & 170.16 & $11,852,154$ \\
\hline gestodene & & $0,06 \mathrm{mg}$ & 0.36 & 10.22 & 122.64 & $8,542,244$ \\
\hline levonorgestrel & \multirow{2}{*}{ Old Generation } & $0,150 \mathrm{mg}$ & 0.17 & 4.88 & 58.56 & $4,078,879$ \\
\hline noretisterona & & $50 \mathrm{mg}$ & 0.14 & 4.02 & 48.24 & $3,360,060$ \\
\hline
\end{tabular}

${ }^{*}$ In combination with ethinylestradiol except for noretisterona which is combined with estradiol.

** Global cost per year if all beneficiaries take the combination analysed. (all prices are expressed in USD)

DDD: Defined daily dose

With a follow up of one year, the number of young female that had thrombotic events (either depth vein thrombosis of lower limbs, thromboembolism or arterial thrombosis) were 77 (Table 3). Of all these 77 women in oral contraception treatment, 75 received combinations with new progestogens and 2 of them used combinations with first or second generation progestogens.
Even considering that the population that receives new combinations was $95 \%$ of all beneficiaries, adjusting these values to 100,000 users; the occurrences of thrombotic events were doubled with the consumption of 3rd and 4 th generation progestogens (Table 3).

Table 3: Thrombotic events according to progestogen consumed

\begin{tabular}{|c|c|c|c|}
\hline $\begin{array}{c}\text { Type of } \\
\text { Progestogen }\end{array}$ & $\begin{array}{c}\text { Total no of } \\
\text { beneficiaries }\end{array}$ & $\begin{array}{c}\text { no of beneficiaries with } \\
\text { thrombotic event after one year } \\
\text { period treatment }\end{array}$ & $\begin{array}{c}\text { Cases of thrombosis every } \\
\mathbf{1 0 0 , 0 0 0} \text { users according to type } \\
\text { of progestogen }\end{array}$ \\
\hline $\begin{array}{c}\text { New progestogen } \\
\text { combination }\end{array}$ & 66,043 & 75 & 11.36 \\
\hline $\begin{array}{c}\text { Old progestogen } \\
\text { combination }\end{array}$ & 3,610 & 2 & 5.54 \\
\hline
\end{tabular}

Hence, the usage of new oral contraceptives combinations increased in $105 \%$ the risk of thrombotic events compared with the old combinations that includes first and second generation progestogen (Table 3 )

\section{DISCUSSION}

An oral combination contraceptive pill is an effective birth control method. In fact, oral contraception is an example of pharmacological effectiveness, with more than $99 \%$ of efficacy among users. It does not matter the type of combination, nor the progestin involve in the combination; the contraceptive efficacy achieved with the different combinations is similar ${ }^{18}$.

Oral contraceptives are medicines with unique characteristics: they are always prescribed to young and healthy people. Combination pills are safe medications and the incidence of serious adverse effects is extremely rare and rare. However, there are severe adverse effects linked to thrombotic events that can put the lives at risk. The combination pill that involves new generation progestin has less androgenic effects but raise up to 3 times the risk of thrombosis. In our research, results show that the use of drosperinone, gestodene, or desogestrel was associated to a significant risk of thrombosis when compared with levonorgestrel or norgestrel ${ }^{2}$.
It is mandatory that the public health or social security of countries all over the world ensure that the female population can fully enjoy sexual activity without the risk of having an unwanted pregnancy or exposing to an interruption of pregnancy.

However, it is unacceptable that having scientific evidence about the higher risk of severe side effects associate to certain combinations pills, the Health systems expose their young and healthy population to unnecessary danger providing coverage for this type of medicines ${ }^{19}$.

It cannot be argued that the decision is associated with the costs of the type of medication provided since, as we show in this paper, the costs of new generation contraceptives are up to $50 \%$ more expensive than those safer; without considering the potential costs associated with the medical treatment of adverse events caused by this option, which would rise even more those costs.

\section{CONCLUSSION}

This paper shows that, among the beneficiaries of the Buenos Aires State Social Security, the users of oral contraceptives that combine new generation progestin denote a greater risk of developing thrombosis events when compared with users of drugs containing levonorgestrel or norgestrel. 
Public reproductive health policies that provide contraceptives to the population are crucial for the effective exercise of rights such as avoiding unwanted pregnancies and reproductive planning. However, health authorities and prescribers should consider significant adverse effects associated with some contraceptive drugs, acknowledging that dispensing medicines that combine estrogens with new generations of progestin may expose to additional and unnecessary levels of risks linked to thrombotic events.

Ethical Approval and Consent to participate: The present study was approved by the Ethical Committee of the Scientific Research Commission - Buenos Aires- Argentina (№ CIC-012/16).

Conflict of Interest: The authors declare that they have no conflict of interest.

Funding: The funds to carry out the work were contributed by the National University of Argentina

Acknowledgements: the authors thank the authorities of the University of Asuncion, University of La Plata and CONICET

Authors' Contributions: Conception and design: LM, LB, GHM; Acquisition, analysis and interpretation of data: GM, SA, MP, GHM, MP; Drafting the article: GM, LB, GHM; Revising it critically for important intellectual content: LM, GM, SA; Approved final version of the manuscript: LB, GHM.

Corresponding Author information: contacts for this paper should be made to corresponding author Gustavo $\mathrm{H}$ Marin. E-mail: gmarin2009@gmail.com

\section{REFERENCES}

1. Ageno W, Squizzato A, Garcia D, Imberti D. 2006 Epidemiology and risk factors of venous thromboembolism. Semin Thromb Hemost. 2006; 32 (7):651658.

2. Dragoman MV, Tepper NK, Fu R, Curtis KM, Chou R, Gaffield ME. 2018. A systematic review and meta-analysis of venous thrombosis risk among users of combined oral contraception. Int J Gynaecol Obstet. 2018; 141(3):287-294.

3. Stegeman BH, de Bastos M, Rosendaal FR. Different combined oral contraceptives and the risk of venous thrombosis: systematic review and network meta-analysis. BMJ. 2013; 347:f5298.

4. Lidegaard $\emptyset$, Løkkegaard E, Svendsen AL, Agger C. Hormona contraception and risk of venous thromboembolism: national follow-up study. BMJ. 2009; 339:b2890.

5. Lidegaard $\varnothing$, Nielsen LH, Skovlund CW, Skjeldestad FE, Løkkegaard E. Risk of venous thromboembolism from use of oral contraceptives containing different progestogens and oestrogen doses: Danish cohort study, 2001-2009. BMJ. 2011; 343: d6423

6. WHO. Venous thromboembolic disease and combined oral contraceptives: results of international multicentre case- control study World Health Organization Collaborative Study of Cardiovascular Disease and Steroid Hormone Contraception. Lancet. 1995; 346(8990):1575-1582.

7. Jick H, Jick SS, Gurewich V, Myers MW, Vasilakis C. Risk of idiopathic cardiovascular death and nonfatal venous thromboembolism in women using oral contraceptives with differing progestogen components. Lancet 1995; 346 (8990):1589-1593.

8. Spitzer WO, Lewis MA, Heinemann LA, Thorogood M, MacRae KD. Third generation oral contraceptives and risk of venous thromboembolic disorders: an international case-control study. Transnational Research Group on Oral Contraceptives and the Health of Young Women. BMJ. 1996; 312 (7023):8388.

9. Jennings V, Haile L, Simmons R, Spieler J, Shattuck D. Perfectand typical-use effectiveness of the Dot fertility app over 13 cycles: results from a prospective contraceptive effectiveness trial, Eur J of Contrac \& Reprod Health Care 2019; 24, 2:148153.

10. CGP-ACOG -Committee on Gynecologic Practice ACOG Committee Opinion Number 540: Risk of venous thromboembolism among users of drospirenone-containing oral contraceptive pills. Obstet Gynecol. 2012; 120(5):12391242.

11. Lidegaard $\varnothing$, Milsom I, Geirsson RT, Skjeldestad FE. Hormonal contraception and venous thrombosis. Acta Obstet Gynecol Scand 2012; 91: 769-78.

12. Krattenmacher R, Knauthe R, Parczyk K, Walker A, Hilgenfeldt U, Fritzemeier KH. Estrogen action on hepatic synthesis of angiotensinogen and IGF-I: direct and indirect estrogen effects. J Steroid Biochem Mol Biol. 1994; 48(2-3):207-214.

13. Cagnacci A. Hormonal contraception: venous and arterial disease.Eur J Contracept Reprod Health Care.2017; 22(3):191-199.

14. Fruzzetti F, De Negri F, Morale M. Activation of coagulation in smoking and non-smoking women using a third-generation oral contraceptive containing desogestrel. Eur J Contracept Reprod Health Care. 1999; 4(3):113-118.

15. Böttiger LE, Boman G, Eklund G, Westerholm B. Oral contraceptives and thromboembolic disease: effects of lowering oestrogen content. Lancet. 1980; 1(8178):10971101.

16. Swanepoel AC, Roberts HC, Soma P, Lindeque BG, Bester J. Hemorheological mechanisms for increased thrombosis in subjects using gestodene. Microsc Res Tech. 2018; 81(12):1489-1500.

17. Van Hylckama Vlieg A, Helmerhorst FM, Vandenbroucke JP, Doggen CJ, Rosendaal FR. The venous thrombotic risk of oral contraceptives, effects of oestrogen dose and progestogen type: results of the MEGA case-control study. BMJ. 2009; 339:b2921.

18. Dinger JC Oral contraceptive effectiveness according to body mass index, weight, age, and other factors. Am J Obstet Gynecol 2009; 201: 263.e1.

19. WHO. World Health Organization. Medical Eligibility Criteria for Contraceptive Use. In. WHO Family Planning. 5th ed. 2015. Geneva, Switzerland. http://www.who.int/ reproductivehealth/publications/family_planning /MEC5/en/ . Accessed June 8, 2020. 